\title{
QUALITY ASSURANCE OF ULTRAFILTERED BONE DATING
}

\author{
Fiona Brock ${ }^{1}$ - Christopher Bronk Ramsey $\bullet$ Thomas Higham \\ Oxford Radiocarbon Accelerator Unit, Research Laboratory for Archaeology and the History of Art, Dyson Perrins Building, \\ University of Oxford, Oxford OX1 3QY, United Kingdom.
}

\begin{abstract}
Ultrafiltration of bone collagen provides a method of purification that can be very effective in reducing environmental contamination from soil-derived amino acids as well as removing degraded collagen or other short-chain proteins. The Oxford Radiocarbon Accelerator Unit (ORAU) first implemented ultrafiltration in the pretreatment of bone material for accelerator mass spectrometry (AMS) radiocarbon dating in 2000. However, the filters themselves contain carbonaceous material, and thus stringent quality control is required to demonstrate that this does not affect the accuracy of the dating. Here, we present quality assurance data from the bone pretreatment and dating program at ORAU, including dates on known-age and background-age bones over a range of sample sizes, and measurements of residual carbon contamination present in the filters after cleaning.
\end{abstract}

\section{INTRODUCTION}

Bone is one of the most commonly dated archaeological materials and a great deal of research has been undertaken into identifying the most effective prescreening and pretreatment methods prior to radiocarbon dating (e.g. Brown et al. 1988; Hedges and van Klinken 1992; Tisnérat-Laborde et al. 2003; Bronk Ramsey et al. 2004). At the Oxford Radiocarbon Accelerator Unit (ORAU), our routine bone pretreatment involves a simple acid-base-acid (ABA) treatment followed by gelatinization and ultrafiltration, and is described in detail in Bronk Ramsey et al. (2004). Briefly:

- Coarsely ground bone powder $(\sim 0.5-1.0 \mathrm{~g})$ is sequentially treated with hydrochloric acid $(0.5 \mathrm{M})$, sodium hydroxide $(0.1 \mathrm{M})$, and hydrochloric acid $(0.5 \mathrm{M})$ with thorough rinsing with ultrapure (MilliQ ${ }^{\mathrm{TM}}$ ) water between each reagent;

- Crude collagen is gelatinized in pH 3 solution at $75^{\circ} \mathrm{C}$ for $20 \mathrm{hr}$;

- The gelatin solution is filtered using a $9-\mu \mathrm{m}$ polyethylene Eezi-filter ${ }^{\mathrm{TM}}$ that has been cleaned by ultrasonicating in ultrapure water for $20 \mathrm{~min}$;

- The filtered gelatin is transferred into a precleaned (see below) ultrafilter (Vivaspin ${ }^{\mathrm{TM}} 15,30 \mathrm{kD}$ MWCO [molecular weight cut off]) and centrifuged at 2500-3000 rpm until $0.5-1.0 \mathrm{~mL}$ of the $>30-\mathrm{kD}$ gelatin fraction remains (typically $20-40 \mathrm{~min}$ );

- This gelatin is freeze-dried and ready for combustion in a CHN analyzer prior to graphitization.

Brown et al. (1988) originally proposed the addition of an ultrafiltration step to Longin (1971) collagen extraction. By selecting only higher molecular weight $(>30 \mathrm{kD})$ proteins, they hoped to remove contaminants that were considered likely to be of relatively low molecular weight, such as short-chain proteins from degraded and potentially contaminated collagen, salt products, fulvic acids, etc. Initial dating of archaeological bone samples using ultrafiltration at ORAU showed that this method more successfully removed contaminants that simple Longin collagen extraction did not remove (Bronk Ramsey et al. 2004; Higham et al. 2006a,b; Jacobi et al. 2006). In addition, the method is simpler to apply than others such as single amino acid dating or ion exchange chromatography. However, the polyethersulferone filter membranes of the ultrafilters are coated with a humectant (glycerol) by the manufacturers to prevent the membrane drying out. This requires effective removal prior to use to avoid contamination.

'Corresponding author. Email: fiona.brock@archaeology-research.oxford.ac.uk. 
It became apparent during an intercomparison exercise between 3 laboratories in late 2002, that known-age samples from dendrochronologically dated coffins were producing dates at ORAU that were 100-300 yr too old for their expected age or context. A thorough investigation revealed that the source of the contamination was the humectant applied to the ultrafilter membrane. The manufacturer's instructions for cleaning the ultrafilters did not result in effective removal of all the humectant. This finding along with a revised cleaning protocol for the ultrafilters (given below) and details of quality control procedures initially implemented were described by Bronk Ramsey et al. (2004).

Bronk Ramsey et al. (2004) suggested that the average offset due to the original cleaning method might well have been as high as a hundred years until the yield rose above $40 \mathrm{mg}$ collagen. This has been confirmed in a major redating exercise. For yields less than $10 \mathrm{mg}$ collagen, the offset seems to have averaged about $200 \mathrm{yr}$, for those greater than $30 \mathrm{mg}$ collagen it reduces to about $55 \mathrm{yr}$, and when yields are greater than $60 \mathrm{mg}$ it drops to about $30 \mathrm{yr}$. Overall, the average shift seems to be about 120 yr. However, in all instances there is a lot of variability in the offsets, with some shifts being greater than the average and some almost not shifted at all; this precludes precise correction of the results. A number of these redeterminations are published and discussed elsewhere (Higham et al. 2004, forthcoming; Bayliss et al. 2007; Bronk Ramsey et al., forthcoming a,b).

Since 2002, we have continued to use ultrafiltration for all bone samples regardless of age, and for redating bone previously analyzed at ORAU and other facilities. It is clearly crucial to implement an effective cleanup of the ultrafilters used in the dating process, and to monitor closely the carbon content of the ultrafilters and test the effectiveness of the cleaning procedures. Here, we present our ultrafilter cleanup procedures and quality assurance data for ultrafilters used and known-age bones dated.

\section{CLEANING ULTRAFILTERS}

The humectant used to coat the filter membranes of the ultrafilters is highly water-soluble. The manufacturers recommend that the glycerol can be removed effectively by centrifuging twice with ultrapure water. When we first began to use the ultrafilters in 2000, we decided to centrifuge 3 times, but when the problems with contamination became apparent we discovered that even this failed to remove all the glycerol. We now clean the ultrafilters as detailed in Bronk Ramsey et al. (2004) as follows:

- Centrifuge twice with ultrapure (MilliQ) water;

- Ultrasonicate in a large volume of ultrapure water for $1 \mathrm{hr}$;

- Centrifuge once with ultrapure water;

- $1 \mathrm{~mL}$ of ultrapure water is then added to 1 filter from each batch cleaned, swirled over the filter membrane, and then removed with a glass pipette for carbon content analysis;

- Centrifuge twice more with ultrapure water.

Ultrafilters are cleaned no more than $24 \mathrm{hr}$ prior to use and are kept wet to prevent from drying out whenever possible.

The water removed for carbon content analysis is combusted in a CHN analyzer on a Chromosorb ${ }^{\circledR}$ pellet. The amount of carbon has remained fairly consistently below $10 \mu \mathrm{g}$ since 2003 , despite changes in ultrafilter batches (Figure 1). "Blank" samples of Chromosorb on which the water is analyzed typically yield $\sim 3 \mu \mathrm{g}$ of carbon. Where greater than $15 \mu \mathrm{g}$ of carbon is detected, the dates produced for the entire batch of bones treated are considered individually, taking into account their expected ages, the ages of other samples from the same site, the ages of the known- or background- 
age bones dated alongside them, and the age of the humectant present in that batch of ultrafilters. If there is any suspicion of contamination from the humectant, additional subsamples of bone undergo full pretreatment and dating. (It should be noted, however, that this has only rarely produced significantly different dates, suggesting that contamination from the ultrafilters was negligible or absent.)

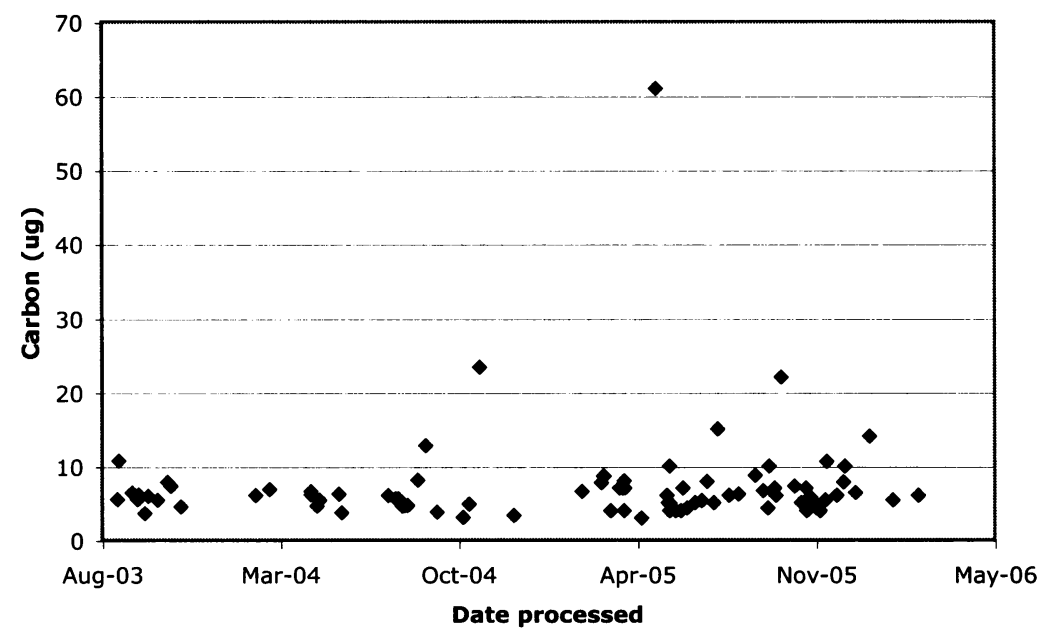

Figure 1 Levels of carbon remaining on ultrafilters after 2 centrifuge rinses, 1-hr ultrasonication in ultrapure water, and a further centrifuge rinse. Where greater than $15 \mu \mathrm{g}$ carbon is detected, the entire batch of bone samples are considered individually.

We also extract and date the glycerol present in each new batch of ultrafilters received at ORAU. Initially, this produced older dates, often $>35 \mathrm{kyr} \mathrm{BP}$, although there were variations within and between batches. However, since 2005 all batches have contained humectant with a modern organic origin (Table 1). The total amount of humectant present within the ultrafilters is not measured, but appears to have increased in recent batches. However, we are confident that our cleanup process remains effective as, excluding 1 background value of $61 \mu \mathrm{g}$ of carbon (which may not have originated from the ultrafilter itself), there is no significant difference in background carbon levels detected between the pre-March 2005 (background age) and the post-March 2005 (modern) ultrafilters.

Table 1 Age of humectant recovered from each batch of ultrafilters used at ORAU since 2003.

\begin{tabular}{lll}
\hline Batch & In use at ORAU & Age \\
\hline 02VS1538 & $2003-2004$ & Ranging from 25,540 to $>35 \mathrm{kyr}$ BP \\
03VS1539 & $2003-2004$ & Ranging from 12,325 to $>35 \mathrm{kyr}$ BP \\
05VS1510 & 2005 & $103.95 \mathrm{pMC}$ \\
05VS1521 & $2005-2006$ & $103.20 \mathrm{pMC}$ \\
06VS1506 & 2006 & $101.46 \mathrm{pMC}$ \\
\hline
\end{tabular}

\section{QUALITY ASSURANCE USING KNOWN-AGE AND BACKGROUND-AGE BONES}

Known-age and background bone samples are routinely analyzed alongside archaeological bone samples in batches. This enables us to monitor a) our precleaning of the ultrafilters used in the pretreatment (regardless of the origin of the humectant) and b) the reproducibility of bone determinations prepared under identical conditions to those unknown-age samples we analyze routinely. 
Bones with a range of sample starting weights are analyzed to consider the reproducibility of dating bones with low collagen yields (about $1-3 \mathrm{wt} \%$ [weight percent] collagen) and to provide a suitable background correction for old ( $>4$ half-lives of ${ }^{14} \mathrm{C}$ ) samples. We pretreat samples of 2 starting masses, a "high" mass ( $600 \mathrm{mg}$ ) similar to that used for most bones dated at ORAU, and a "low" mass (typically of $\sim 200 \mathrm{mg}$ ) to simulate low collagen yields. To test for low levels of old contaminant, we treat and date pig bones recovered from the wreck of the Mary Rose, Henry VIII's flagship. The Mary Rose sank in AD 1545, and so the bones should yield a ${ }^{14} \mathrm{C}$ age of $\sim 311 \mathrm{BP}$. Collagen yields and ages of ultrafiltered Mary Rose pig bones are presented in Figure 2.

\section{Known-Age Sample (Mary Rose pig bone)}

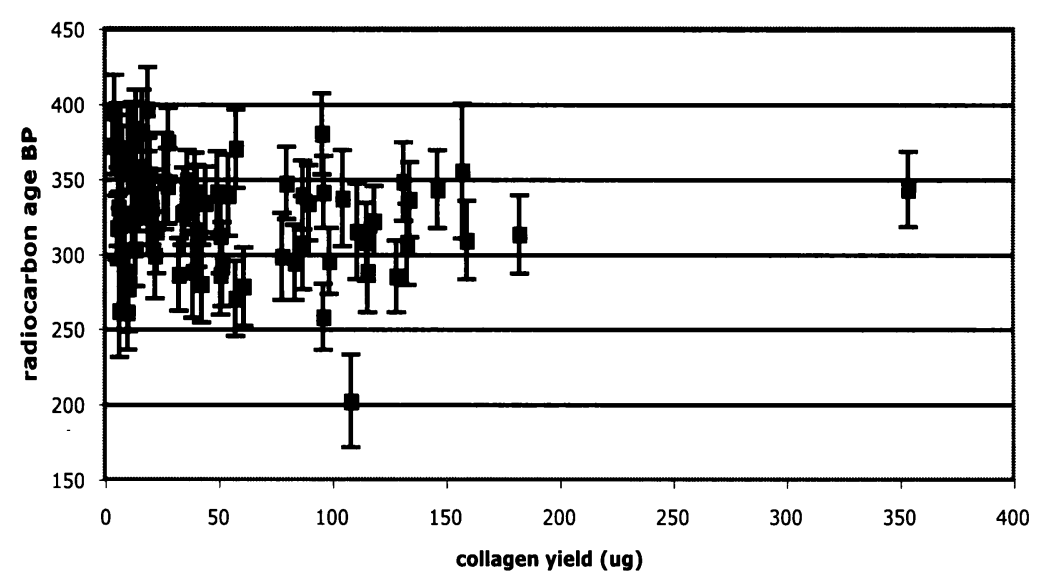

Figure 2 Dates from known-age pig bones found on the wreck of the Mary Rose (sank in AD 1545, so should be $\sim 311 \mathrm{BP}$ ) analyzed using ultrafiltration since 2003.

We also routinely date high and low mass samples of 2 Alaskan bison bones of background age alongside each batch of bones treated (Figure 3a,b). Where these bones yield erroneous ages $(>0.5 \mathrm{pMC})$, low-yielding or old samples are repeated where possible from the start of the pretreatment process. These results may indicate contamination by modern humectant.

\section{Additional Quality Assurance Checks}

In addition to the procedures that we follow to identify any contamination of collagen from ultrafilter humectant, we carry out several other quality assurance checks during and after our bone pretreatment preparation (see van Klinken 1999). These include an assessment of the weight percent of collagen in each sample. Any sample yielding $<10 \mathrm{mg}$ of collagen or $<1 \%$ of the starting weight of bone powder is automatically failed. However, "low" mass quality assurance samples frequently fall below this threshold and therefore test the accuracy of the method over the full range of acceptable sample sizes. The collagen is combusted using a $\mathrm{CHN}$ analyzer, which enables an assessment of $\mathrm{C}: \mathrm{N}$ atomic ratios, the \% carbon and nitrogen of the material, as well as the stable isotopes of carbon and nitrogen. These data are collected routinely for all samples. The acceptable range for C:N ratios at ORAU is 2.9-3.5 (van Klinken 1999). High C:N ratios result either in the failing of the bone or lead to its repeat analysis. 
a)

Alaskan background bone 1 (vertebra)

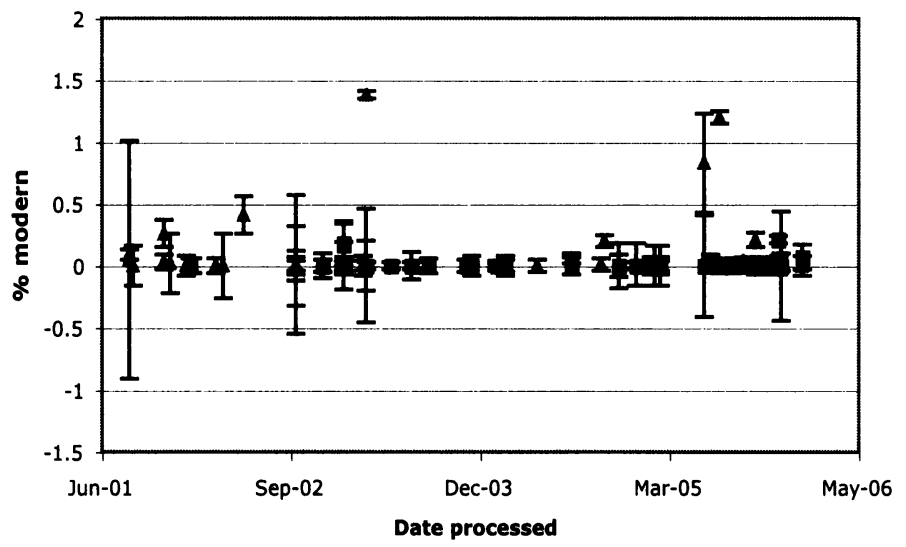

low mass

$\Delta$ high mass

b)

Alaskan background bone 2 (longbone)

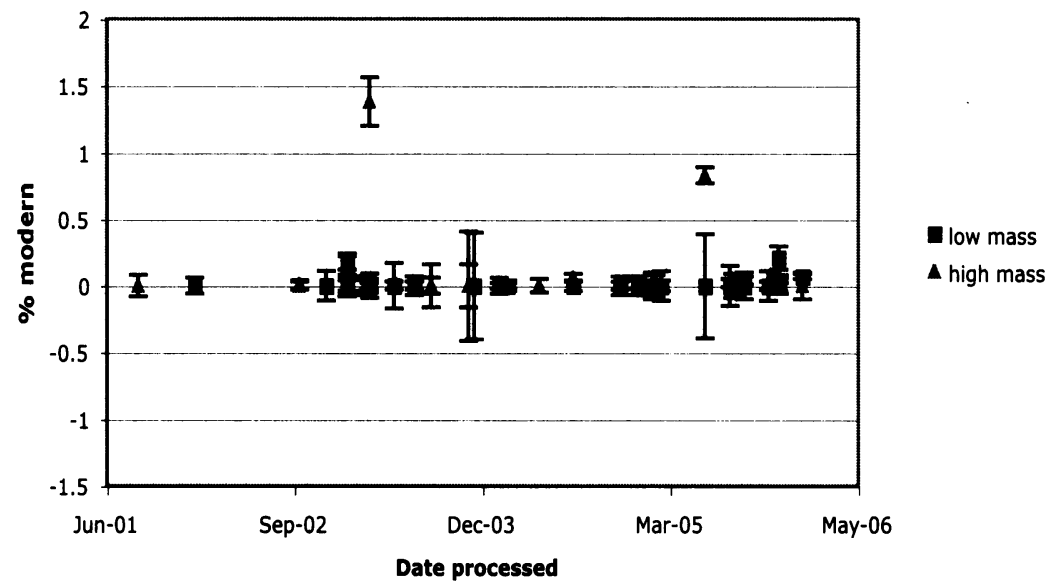

Figure 3 Background-age Alaskan bison bones (a: vertebra; b: longbone) are dated alongside every batch of bones treated at ORAU. Where erroneous dates are produced $(>0.5 \mathrm{pMC})$, old or low-yielding samples are retreated where possible (NB: a sample-size dependent background has already been subtracted from these data).

\section{CONCLUSIONS}

While ultrafiltration will not remove high-molecular weight contaminants, such as cross-linked humic-collagen complexes, it is an effective method of removal of low-molecular weight contaminants from bone collagen. The use of ultrafiltration to redate some bones previously dated at ORAU that were suspected of being problematic due to low collagen yields or aberrant $\mathrm{C}: \mathrm{N}$ ratios has resulted in some substantial revisions. These are usually restricted to bone of Paleolithic age and have previously been reported (Higham et al. 2006a,b; Jacobi et al. 2006). In addition, when ultrafiltered gelatin determinations are compared with bone determinations obtained in other laboratories using the Longin collagen method, there are often significant differences that we conclude are probably related to improved contaminant removal using ultrafiltration (see Bronk Ramsey et al. 2004).

We suspect that this may be evidence of a more general pattern amongst the corpus of bone determinations in archaeology that could be improved by the wider use of this method in bone pretreat- 
ment chemistry. Jöris et al. (2003) have noted that, where charcoal and bone are dated from identical contexts in Paleolithic Europe, bone often produces ages that are younger by comparison. Our results would suggest that because ultrafiltration often increases the measured age compared with Longin collagen techniques, its adoption could contribute to the resolution of this problem.

However, the filters do contain a carbon-containing humectant that must be removed prior to the ultrafiltration of archaeological bone gelatin. The age (and organic origin) and amount of the humectant varies within and between batches of ultrafilters. The manufacturer-recommended cleaning procedures are insufficient to remove all the humectant from the ultrafilters, and so we implement a more rigorous procedure.

Because of the presence of this humectant within the ultrafilters and its variation between batches of ultrafilters, it is important to apply consistent quality assurance checks alongside the pretreatment of bone collagen samples for accelerator mass spectrometry (AMS) dating to allow the detection of potential contamination during the pretreatment process. We implement a range of checks, including monitoring the level of carbon present in cleaned ultrafilters, and dating known-age and background-age bones alongside each batch of bones pretreated, in order to ensure the accuracy of the determinations made by this method.

\section{ACKNOWLEDGMENTS}

We acknowledge the careful laboratory work of the ORAU staff, especially A Bowles, C Tompkins, and J Davies, and the Mary Rose Trust for their kind donation of bone specimens.

\section{REFERENCES}

Bayliss A, Bronk Ramsey C, van der Plicht J, Whittle A. 2007. Bradshaw and Bayes: towards a timetable for the Neolithic. Cambridge Archaeological Journal 17(Supplement S1):1-28.

Bronk Ramsey C, Higham T, Bowles A, Hedges R. 2004. Improvements to the pretreatment of bone at Oxford. Radiocarbon 46(1):155-63.

Bronk Ramsey C, Higham TFG, Whittle A, Bartosiewicz L. Forthcoming a. The radiocarbon chronology. In: Whittle A, editor. The Early Neolithic on the Great Hungarian Plain: Investigations of the Körös Culture Site of Ecsegfalva 23, Co. Békés. Budapest: Institute of Archaeology.

Bronk Ramsey C, Higham TFG, Pearson J. Forthcoming b. Bone pre-treatment by ultrafiltration: a report on unintended age offsets introduced by the method. Eastney, Portsmouth, UK: English Heritage Centre for British Archaeology report.

Brown TA, Nelson DE, Vogel JS, Southon JR. 1988. Improved collagen extraction by modified Longin method. Radiocarbon 30(2):171-7.

Hedges REM, van Klinken GJ. 1992. A review of current approaches in the pretreatment of bone for radiocarbon dating by AMS. Radiocarbon 34(3):279-91.

Higham TFG, Bronk Ramsey C, Petchey FJ, Tompkins C, Taylor M. 2004. AMS radiocarbon dating of Rattus exulans bone from the Kokohuia site (New Zealand). In: Higham T, Bronk Ramsey C, Owen C, editors. Radiocarbon and Archaeology, Proceedings of the 4th
Symposium, Oxford 2002. Oxford: Oxbow. p 135-51.

Higham TFG, Jacobi RM, Bronk Ramsey C. 2006a. AMS radiocarbon dating of ancient bone using ultrafiltration. Radiocarbon 48(2):179-95.

Higham TFG, Bronk Ramsey C, Karavanić I, Smith FH, Trinkaus E. 2006b. Revised direct radiocarbon dating of the Vindija $G_{1}$ Upper Paleolithic Neandertals. Proceedings of the National Academy of Sciences of the United States of America 103(3):553-7.

Higham TFG, Bronk Ramsey C, Brock F, Baker D, Ditchfield P. Forthcoming. Radiocarbon dates from the Oxford AMS system. Archaeometry. Datelist 32.

Jacobi RM, Higham TFG, Bronk Ramsey C. 2006. AMS radiocarbon dating of Middle and Upper Palaeolithic bone in the British Isles: improved reliability using ultrafiltration. Journal of Quaternary Science 21(5): 557-73.

Jöris O, Álvarez Fernández E, Weninger B. 2003. Radiocarbon evidence of the Middle to Upper Palaeolithic transition in southwestern Europe. Trabajos de Prehistoria 60(2):15-38.

Longin R. 1971. New method of collagen extraction for radiocarbon dating. Nature 230(5291):241-2.

Tisnérat-Laborde N, Valladas H, Kaltnecker E, Arnold M. 2003. AMS radiocarbon dating of bones at LSCE. Radiocarbon 45(3):409-19.

van Klinken GJ. 1999. Bone collagen quality indicators for palaeodietary and radiocarbon measurements. Journal of Archaeological Science 26(6):687-95. 